\title{
Correlation of Biochemical Parameters with Cytomorphological Grading in Hashimoto's Thyroiditis
}

\author{
Amrita Dhakal Sharma ${ }^{1}$, Navya B.N ${ }^{2 *}$ and Sathyavathi R. Alva ${ }^{3}$ \\ 'Postgraduate student, Department of pathology, KVG Medical college and hospital, India \\ ${ }^{2}$ Professor, Department of Pathology, KVG Medical College and Hospital, India \\ ${ }^{3} \mathrm{HOD}$ and Professor, Department of Pathology, KVG Medical College and Hospital, India
}

\section{ABSTRACT}

Background: Hashimoto's thyroiditis (HT) is one of the most common cause of hypothyroidism in iodine sufficient areas. Diagnosis of HT is based on clinical, cytomorphological and biochemical parameters. Fine Needle Aspiration Cytology (FNAC) of thyroid provides a safe and accurate method for diagnosis of HT. Cytological grading of HT helps in assessing the severity of the disease and can predict the thyroid functional status.

Methods: Retrospectively, 50 diagnosed cases of HT on FNAC were studied over a period of 6 months in a tertiary care hospital. Clinical, biochemical parameters such as T3, T4 and TSH values were collected. Cytological grading of FNAC smears was done based on Bhatia et al cytological grading system into three grades. These grades were compared with the clinical and biochemical parameters of HT.

Result: Of 50 patients, 47 were females. Maximum number of cases were seen between $36-45$ years. Most of the patients presented with goiter. 31 out of $50(62 \%)$ cases were grade II thyroiditis, of them most cases were hypothyroid. 17 out of 50 cases (34\%) were grade I thyroiditis, of which most cases were euthyroid biochemically.

Conclusion: Higher the grades of HT in cytology the more abnormal are the biochemical parameters. A combined approach of cytological grading along with clinical and biochemical parameters can detect subclinical hypothyroid state which provides a guide to therapy.

\section{Keywords: FNAC, Hashimoto's Thyroiditis, Autoimmune Disorder, Cytomorphology.}

\section{Introduction}

In 1912 Hakaru Hashimoto first described Hashimoto's thyroiditis(HT). HT is one of the most common causes of hypothyroidism and is also known as chronic lymphocytic thyroiditis or autoimmune thyroiditis. ${ }^{[1]}$ This disorder is prevalent between 45- 65 years of age, has a prevalence rate of $1-4 \%$ and incidence of 30-60/1 lakh population per year with a female predominance of $10: 1$ to $20: 1$. $^{\text {[2] }}$ HT has a strong genetic association with concordance of disease in as many as $40 \%$ of monozygotic twins. The polymorphism in HT is linked to CTLA4 gene. It is an immunologically mediated organ-specific inflammatory disease characterized by infiltration of lymphocytes and formation of Hürthle cells ${ }^{[3]}$

Diffuse or nodular swelling of the thyroid gland is seen clinically, most patients are usually asymptomatic while some of them present with symptoms of hypothyroidism. [1] During the course of the disease, hypothyroidism develops, it is preceded by transient thyrotoxicosis causing hashitoxicosis. ${ }^{[3]}$

Diagnosis of HT is based on clinical features, thyroid function test, anti-thyroid peroxidase antibody test and on fine needle aspiration cytology(FNAC). ${ }^{[4]}$ FNAC is a simple, cost-effective and safe procedure. It is specific and sensitive in diagnosing and grading HT which helps in assessing the severity of the disease and can also predict the thyroid functional status. ${ }^{[5]}$ Therefore FNAC remains the gold standard test despite several tests for diagnosis of HT. ${ }^{[6]}$ This study is aimed at grading the thyroiditis on FNAC and correlating the cytological grades with the clinical and biochemical findings .

\section{Objectives}

1. Cytological Grading of Hashimoto's Thyroiditis.

2. Compare the cytological grade with the biochemical (T3, T4 and TSH) levels and clinical presentations.

\section{Materials and Methods}

A retrospective study was done for 6 months on 50 patients diagnosed as Hashimoto's thyroiditis on FNAC in Department of Pathology, KVG Medical College and Hospital.

\section{Inclusion criteria:}

1. Diagnosed cases of Hashimoto's thyroiditis based on FNAC. 


\section{Exclusion criteria:}

1) Patients with cytology of multinodular or colloid goiter were excluded in the study.

2) Patents who were receiving medicine which are known to interfere with the thyroid function.

Methods: Clinical details like age, sex, clinical presentation and nature of thyroid enlargement along with the biochemical values of the Thyroid function test such as T3, T4 and TSH (TFT) estimated by using enzyme linked immunosorbent assay i.e. Minividas (Vitek Immunodiagnostic Assay System analyzer) were collected from the various archives of our institution. The patients were graded as euthyroid, hypothyroid or hyperthyroid depending upon the reference value used. The reference normal range used were $\mathrm{T} 4=4.4-11.8 \mu \mathrm{g} / \mathrm{dl}$, T3 $=0.64$ $2.15 \mathrm{ng} / \mathrm{dl}$ and $\mathrm{TSH}=0.25-5 \mu \mathrm{IU} / \mathrm{ml}$. Air dried and ethanol fixed smears stained with Hematoxylin and eosin and Leishman's stain were collected. Two pathologist examined the cytological smears examined in detail and adequacy was judged using Hamburger's criteria. ${ }^{[7]}$ Bhatia et $\mathrm{al}^{[6]}$ grading system was used to grade to the thyroiditis. Cytological grades were later correlated with the clinical/ biochemical findings using Pearson's correlation system.

Bhatia et al cytological grading. ${ }^{[6]}$

\begin{tabular}{|l|l|}
\hline Grades & Morphological features \\
\hline 0 & No lymphoid follicles \\
\hline I & $\begin{array}{l}\text { Few lymphoid cells infiltrating the follicles } \\
\text { Increased number of lymphocytes in } \\
\text { background. }\end{array}$ \\
\hline II & $\begin{array}{l}\text { Moderate lymphocytic infiltration with Hurthle } \\
\text { cell change/ giant cells/ anisonucleosis. }\end{array}$ \\
\hline III & $\begin{array}{l}\text { Florid lymphocytic infiltrate with germinal } \\
\text { center formation, very few follicular cells left. }\end{array}$ \\
\hline
\end{tabular}

\section{Result}

A total of $50(n=50)$ patients with Hashimoto's thyroiditis were included in the study, of these 47 were females and the remaining 3 were males, which indicated a significantly higher percentage of females having HT as compared to men (9.4:6). The patients age ranged from 15 to 56 years. 7 were in 15-25-year age group followed by 12 patients in the age group of 26-35 years while the maximum number of cases (15) were observed in the age group of $36-45$ years. 9 cases were seen in the age group of 46-55 years and 7 cases were seen in $>56$ years (Table 1 ). The majority of cases were seen noted in the $2^{\text {rd }}-4^{\text {th }}$ decade.

Study showed diffuse thyroid enlargement in 5 cases, while 6 cases presented with weight gain complaint. The most common presentation was diffuse enlargement of thyroid gland $(66 \%)$ followed by difficulty in swallowing $(12 \%)$ and weight gain (24\%) (Table 2).

Table 3 shows distribution of cases as per hormonal status of the patients. T3, T4 and TSH level were determined in all 50 cases. $54 \%$ presented with hypothyroid status, $28 \%$ presented with euthyroid status and $18 \%$ presented with hyperthyroid status. The most common presentation was hypothyroid status followed by euthyroid status and the least common presentation was hyperthyroid status hormonally/biochemically.

Table 4 shows distribution of cases as per cytological grades. Maximum number of patients $(62 \%)$ presented with moderate lymphocytic infiltrate with evidence of follicular destruction, Hurthle cell change, giant cells i.e grade II thyroiditis followed by grade I characterized by mild lymphocytic infiltration (28\%) and grade III (18\%) is characterized by dense infiltrates with germinal centers and few follicular cells presented with hyperthyroidism.

Comparison of grades of Hashimotos thyroiditis with biochemical parameters is outlined in Table 5. 17 cases had grade I thyroiditis, of which 12 were euthyroid, 4 were hypothyroid and 1 was hyperthyroid biochemically. Euthyroid was the most common presentation in grade I HT. 31 cases (grade II thyroiditis), out of which 2 were euthyroid, 21 cases were hypothyroid and 8 cases were hyperthyroid. Hypothyroidism was the most common presentation in grade II HT, Out of which 2 cases of grade III HT 2 were hypothyroid.

As revealed by Pearsons Correlation, our study showed no association between cytological grade and biochemical parameter statistically but clinically it was significant.

\section{Discussion}

HT diagnosis is important as it is an autoimmune disease which leads to destruction of thyroid follicles and patients becomes hypothyroid. Maximum number of the patients diagnosed with HT in our study were in $2^{\text {nd }}-4^{\text {th }}$ decade of life, which is similar to study conducted by Sood $\mathrm{N}$ et al ${ }^{[8]}$. The reported male to female ratio was 9.4:6 in our study which showed a higher incidence of the disease amongst females. A similar finding was reported by Singh $N$ et al ${ }^{[10]}$ in his study. On clinical examination most of the patients in our study presented with a diffuse goiter while few cases presented with asymmetrical thyroid enlargement. 36\% of patients presented with symptoms of goiter and $66 \%$ had diffuse thyroid enlargement. The finding was similar to study done by Bhatia A et al ${ }^{[6]}$. Cases with euthyroid status showed asymmetrical thyroid enlargement. Friedman et al ${ }^{[11]}$ found nodular presentation in as many as $80 \%$ of their 
Table 1: Distribution of cases as per age and sex.

\begin{tabular}{|c|c|c|c|}
\hline Age interval & No of Cases & Male & Female \\
\hline $15-25$ & $7(14 \%)$ & 0 & 7 \\
\hline $26-35$ & $12(24 \%)$ & 1 & 11 \\
\hline $36-45$ & $15(30 \%)$ & 0 & 8 \\
\hline $46-55$ & $9(18 \%)$ & 1 & 6 \\
\hline$>56$ & $7(14 \%)$ & 1 & $\mathbf{3}$ \\
\hline
\end{tabular}

Table 2: Distribution of cases as per clinical features and cytological grading.

\begin{tabular}{|c|c|c|l|}
\hline Grades & No of Patients & Diffuse enlargement of thyroid & Symptoms \\
\hline I & 17 & 5 of 17 & $\begin{array}{l}9 / 17 \text { were asymptomatic; } 6 \text { had weight gain, 2had } \\
\text { difficulty in swallowing. }\end{array}$ \\
\hline II & 31 & 27 of 31 & $\begin{array}{l}22 / 31 \text { were asymptomatic; } 6 \text { had weight gain, } 3 \text { had } \\
\text { difficulty in swallowing. }\end{array}$ \\
\hline II & 2 & 1 of 2 & $1 / 2$ were asymptomatic; 1 had difficulty in swallowing. \\
\hline & 50 & 33 of 50 & $32 / 50$ were asymptomatic. \\
\hline
\end{tabular}

Table 3 shows distribution of cases as per hormonal status of the patients.

\begin{tabular}{|c|c|c|}
\hline Type of thyroidism & Frequency & Percentage \\
\hline Hypothyroidism & 27 & 54.0 \\
\hline Hyperthyroidism & 09 & 18.0 \\
\hline Euthyroid & 14 & 28.0 \\
\hline Total & $\mathbf{5 0}$ & 100.0 \\
\hline
\end{tabular}

Table 4: Distribution of cases as per cytological grading.

\begin{tabular}{|c|c|c|}
\hline Cyto & Frequency & Percentage \\
\hline Grade I & 17 & 34.0 \\
\hline Grade II & 31 & 62.0 \\
\hline Grade III & 2 & 4.0 \\
\hline Total & $\mathbf{5 0}$ & $\mathbf{1 0 0 . 0}$ \\
\hline
\end{tabular}

Table 5: Distribution of cases as per cytological grading and biochemical parameter.

\begin{tabular}{|c|c|c|c|}
\hline Grades & Euthyroid & Hypothyroid & Hyperthyroid \\
\hline I & 12 & 4 & 1 \\
\hline II & 2 & 21 & 0 \\
\hline III & 0 & 2 & $\mathbf{9}$ \\
\hline Total & $\mathbf{1 4}$ & $\mathbf{2 7}$ & 0 \\
\hline
\end{tabular}




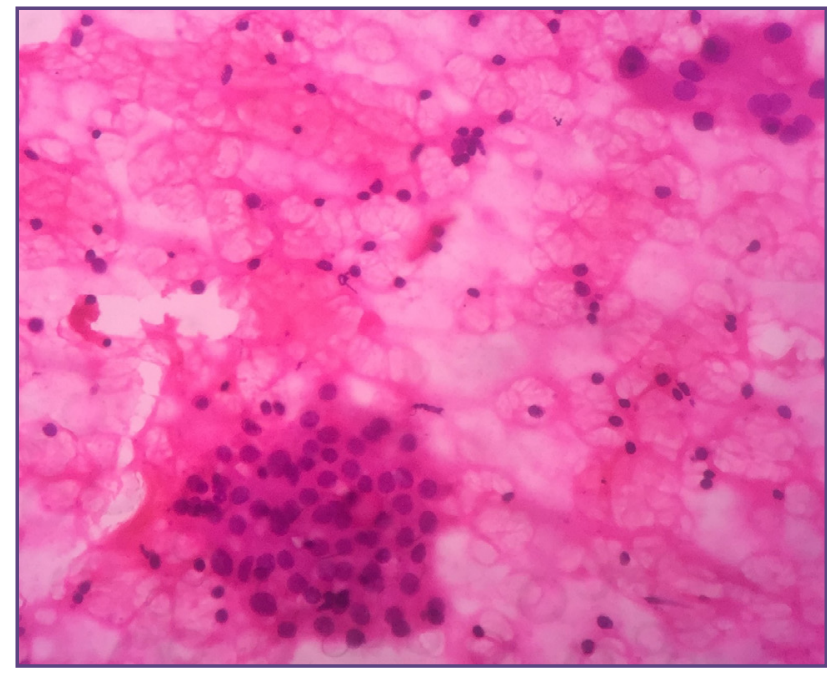

Fig. 1: (10X magnification, H \&E Stain) shows Grade 1 thyroiditis displaying lymphocytes between the follicles and lymphocytes in the background.

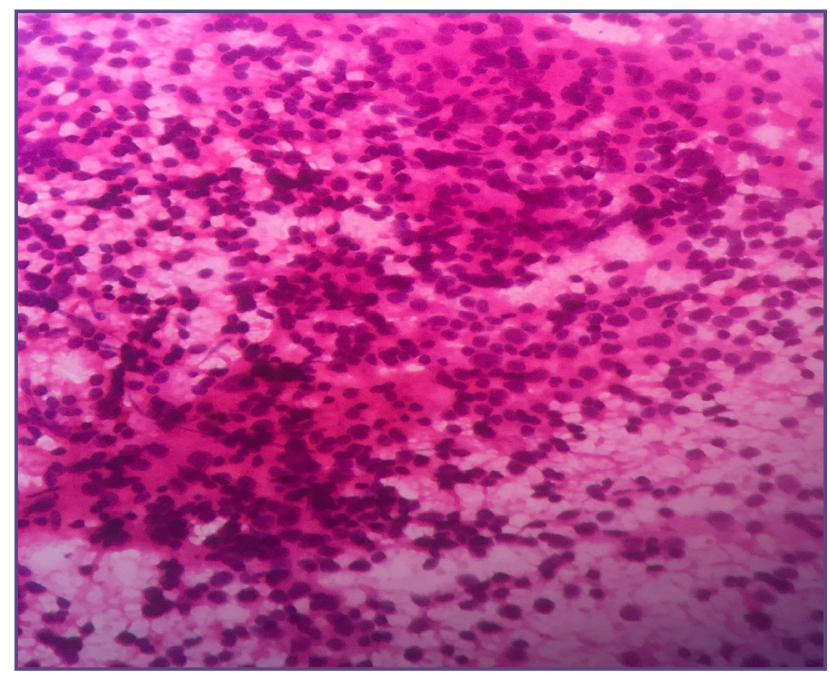

Fig. 3: (10xmagnification, H\&E Stain) shows florid lymphocytes and follicular destruction.

patients. In early stage of disease nodularity is the sole presentation when clinical and hormonal changes are not established. Nodularity incidence was low in our study as the patients had clinical disease, therefore the patients presented with diffuse thyroid swelling. Majority of patients in our study were hypothyroid (62\%) which was very similar to study done by Ekambaram $\mathrm{M}$ et al ${ }^{[12]}$ where $84 \%$ of patients were hypothyroid. Evidence of destruction of follicular epithelial cells by the lymphocytes in association with varying degrees of Hurthle cell change forms the basis for cytological diagnosis of HT. There are two Cytological patterns in HT which corresponds to different phases of the disease: the first one is the - Classical HT, wherein the background shows increased lymphocytic infiltrates with

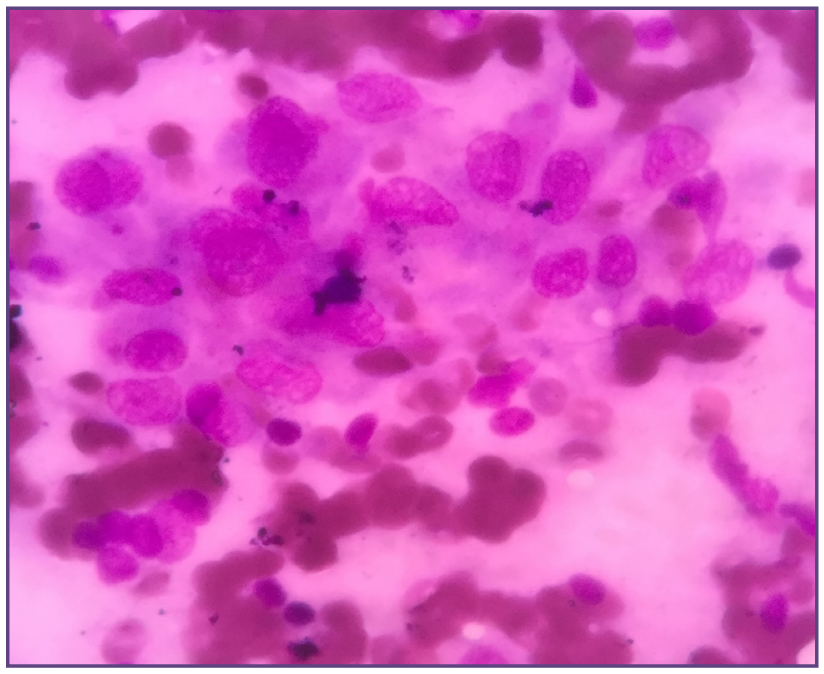

Fig. 2: (40X magnification, H\&E Stain) shows Grade II thyroiditis showing anisonucleosis and hurthle cells.

follicular clusters infiltrated by lymphocytes. Second one is - Florid lymphocyte pattern wherein different stages of maturation of lymphocytes are found. In our study most of the patients with grade I thyroiditis (14\%) were euthyroid $(24 \% \%) .31 \%$ of Grade II thyroiditis cases presented with hypothyroid status $(21 \%)$ which is similar to study done by Ekambaram $\mathrm{M}$ et $\mathrm{al}^{[12]}$ and Rathi $\mathrm{M}$ et al ${ }^{[5]}$ where majority of patients presented with euthyroid thyroid and hypothyroid status in grade I and grade II thyroiditis. The euthyroid status in grade I thyroiditis could be due to lesser number of follicular cell destruction and lymphocytic infiltration and the hypothyroid status in grade II thryoiditis is due to progressive loss of follicular cells and their replacement by the lypmhoplasmacytic infiltrate. In grade III thyroiditis( $2 \%$ ) most cases were hypothyroid(2\%) which is similar to study done by P. Ashwin et al. ${ }^{[13]}$ Higher grades of thyroiditis is associated with abnormal hormonal or biochemical assay. Though our study was significant clinically statistically it was not significant.

Limitation of the study: Ultrasonography and Anti thyroid antibody study could not be done in this study for correlation. Retrospective design is associated with bias.

\section{Conclusion}

Hashimotos Thyroiditis is one of the most common cause for hypothyroidism. FNA being simple, cost effective has improved the preoperative assessment of the thyroid lesions and has become a specific diagnostic tool in HT. HT with higher cytological grades is associated with more abnormal biochemical parameters. Hence, a combined approach of clinical, biochemical and cytologic grading in HT helps in detecting early stages of HT and can also provide guide to treatment. 


\section{Acknowledgements}

Assistant Professor- Dr. Shalu Thomas, Dr. Anjali, Technicians and DMLT students

\section{Reference}

1. Kudva R, Kishore M. Hashimoto's Thyroiditis: A Correlation of Cytolomorphology with Clinical, Biochemical \& Radiological Findings. International Journal of Science and Research. 2015;4(2):1771-4.

2. Gayathri BN, Kalyani R, Harendra KM, Krishna PK. Fine needle aspiration cytology of Hashimoto's thyroiditis-A diagnostic pitfall with review of literature. Journal of Cytology/Indian Academy of Cytologists. 2011 Oct;28(4):210.

3. The Endocrine System, Robbins and Cotran Pathologic Basis of Diseases, South-East Asia Edition V.Kumar, A.K Abbas pp1073-1139, Elsevier, New Delhi, India ,9th Edition, 2014.

4. Prasannan M, Kumar SA. International Journal of Sciences \& Applied Research.

5. Rathi M, Ahmad F, Budania SK, Awasthi S, Kumar A, Dutta S. Cytomorphological aspects of Hashimoto's thyroiditis: Our experience at a tertiary center. Clinical Medicine Insights: Pathology. 2014 Jan; 7:CPath-S13580.

6. Bhatia A, Rajwanshi A, Dash RJ, Mittal BR. Lymphocytic Thyroiditis-is cytological grading significant? A correlation of grades with clinical, biochemical, ltrasonographic and radionuclide parameters. Cytojournal. 2007;4:10.
7. Hamburger JI, Husain MU, Nishiyama R, Nunez C, Solomon D. Increasing the accuracy of fine-needle biopsy for thyroid nodules. Archives of pathology \& laboratory medicine. 1989 Sep;113(9):1035-41.

8. Sood N, Nigam JS. Correlation of fine needle aspiration cytology findings with thyroid function test in cases of lymphocytic thyroiditis. Journal of thyroid Research. $2014 ; 2014$.

9. Chandanwale SS, Nair R, Gambhir A, Kaur S, Pandey A, Shetty A, Naragude P. Cytomorphological Spectrum of Thyroiditis: A Review of 110 Cases. Journal of thyroid

10. Singh N, Kumar S, Negi VS, Siddaraju N. Cytomorphologic Study of Hashimoto's Thyroiditis and Its Serologic Correlation. Acta cytologica. 2009;53(5):507-16.

11. Friedman M, Shimaoka K, Rao U, Tsukada K, Gavigan M, Tamura K:Diagnosis of lymphocytic thyroiditis(nodular presentation) by needle aspiration. Acta Cytolo1981,25:513-22.

12. Ekambaram M, Kumar B, Chowdhary N, Siddaraju N, Kumar S. Significance of eosinophils in diagnosing Hashimoto's thyroiditis on fine-needle aspiration cytology. Indian Journal of Pathology and Microbiology. $2010 \mathrm{Jul}$ 1;53(3):476

13. Khageshan A.P, Muzaffer Z. Cytomorphological, Biochemical and Raiological Correlation in Hashimoto's Thyroiditis. Indian Journal of Pathology and Oncology.2016Jan;3(1):73-6.

*Corresponding author:

Navya B.N, Professor, Department of Pathology, KVG Medical College and Hospital, Sullia, 574327, India

Email: navyabm@rediffmail.com,

Financial or other Competing Interests: None. 